\title{
Understanding Burdens and Developing Hope
}

Jessica N. Ricketts

rickets_jessica@hotmail.com

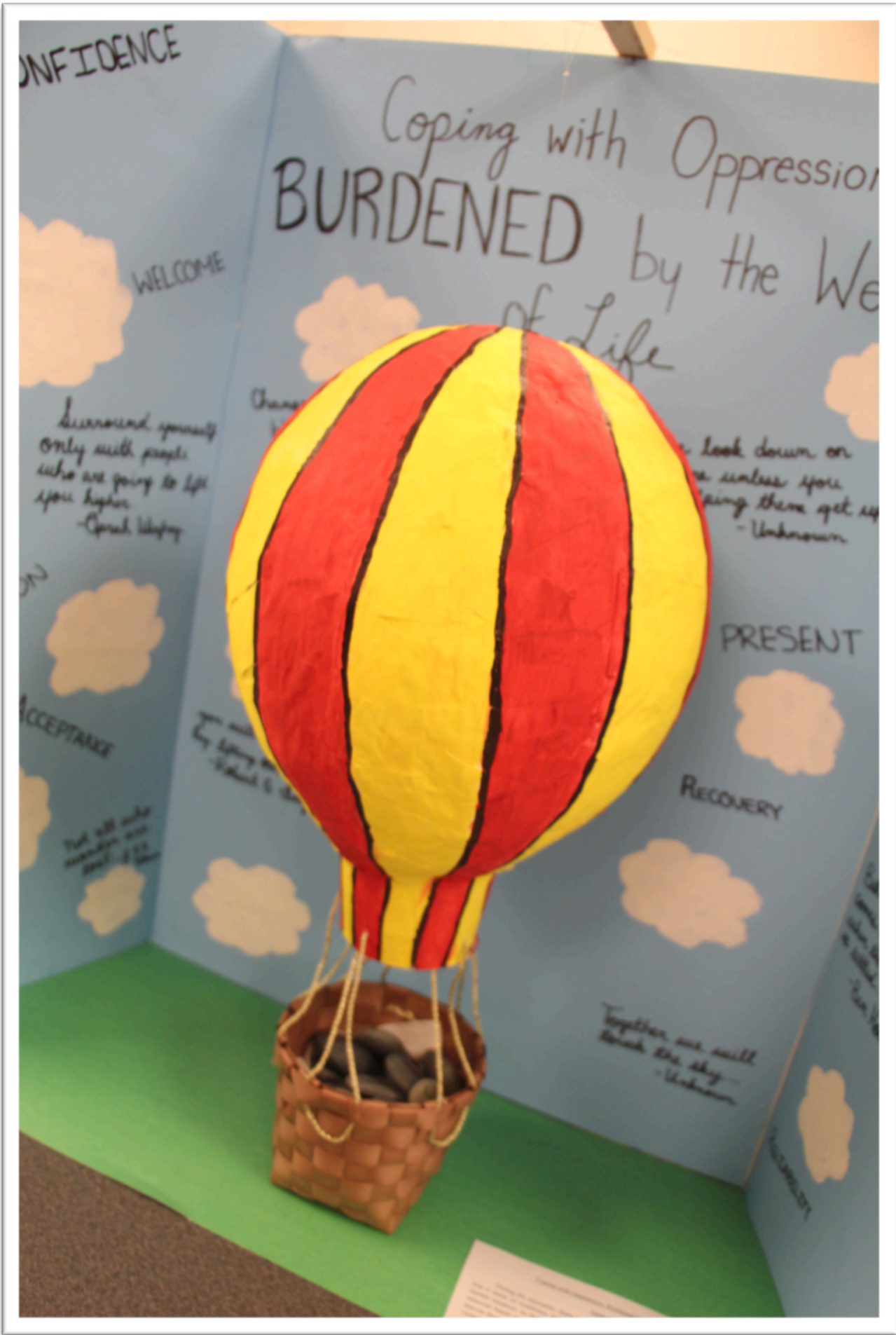

Cultural and Pedagogical Inquiry, Summer 2018, 10(1), pp. 38-39

ISSN 1916-3460 C 2018 University of Alberta

http://ejournals.library.ualberta.ca/index.php/cpi/index 
Empty feelings often occur as a result of the environments in which many clients live. In such environments one may feel lonely and abandoned. One may sense hurt and loss. In working with clients, it is common to observe barriers they encounter, such as, multiple relationship strains, drug and alcohol addictions, and mental health issues, to name a few. A social work student is also held down, due to a lack of work related experiences which may create negative emotions. The art piece I have created identifies these factors and the attendant burdens.

\section{Description of Image}

Hot air balloons represent freedom; the ability to escape, and embrace your surroundings. I placed the heavy rocks with negative words written on them in the balloon's basket. They represent how barriers are capable of holding someone back from experiencing positivity and peace. The sky represents, on one hand, the place where many privileged people are, and on the other hand, the place where the underprivileged may yearn and long to be. All of the rocks speak to the important relationships between the social work student and client. There is one balloon held down by all of the rocks. If some rocks were removed from the basket, either some representing the client, or the student, the balloon would be much closer to lifting off the ground and launching itself, into the sky.

\section{Awareness and Use of Self}

My visual work represents that I felt disempowered as a student with a lack of work experience. Throughout many encounters as a new intern, I felt worried, inexperienced, unwelcome, and doubtful. These words are represented as the rocks in my artwork. The negative factors contributed to the weight that was holding me back from successfully participating in each visit during the field placement. I realized that unfortunately, I lacked the confidence and knowledge to make successful client interventions. Removing some of the rocks from the basket would represent moving forward throughout my placement and career. Hopefully, by gaining professional experience and developing the types of skills required to move through existing barriers, one day, I will be able to focus on supporting clients and assisting their progress. 